\title{
Inteligência Artificial, Tecnologias Informacionais e seus possíveis impactos sobre as Ciências Sociais*
}

TOM DWYER *

\section{Introdução}

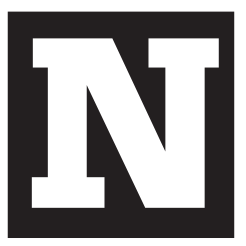

o começo de 1999, estive visitando uma das mais informatizadas Universidades inglesas e, depois de trabaIhar durante alguns dias na sua biblioteca central e nos seus centros de computação, dei-me conta de que os recursos disponíveis ao pesquisador eram enormes. Perguntei-me como seria ser professor numa Universidade onde os alunos poderiam, poucos minutos depois da aula, conferir todos os dados que tinha sido passados, para chegar na próxima aula até com perguntas embaraçosas. Ou seja, percebi que lá as possibilidades oferecidas pela tecnologia tinham forçado uma modificação na base da relação professor-aluno, na qual o papel tradicional do professor era transmitir conhecimento e o do aluno, receber. Perguntei para o professor que me tinha convidado qual era a atual relação professor-aluno? Ele me respondeu $S A$, perguntei $S A$ ? Pois é ele respondeu Some e acha. Ou seja, o professor não fornece mais as informações, orienta o aluno e o ajuda a entender tudo o que descobre nas suas pesquisas. Pensei em professores que conheço em vários países, que só ensinam sobre o mundo a partir de livros e dados desatualizados; como eles seriam vistos pelos alunos se trabalhassem numa Universidade com

\footnotetext{
* Paperapresentado pela primeira vez no Congresso da Sociedade Brasileira de Sociologia em agosto de 1999 em Porto Alegre. Novas versões foram apresentadas no Congresso da SBPC e SBS de Brasília em julho de 2000, na FAFICH/UFMG e no IFCH/Unicamp no decorrer de primeiro semestre de 2000 e em agosto de 2000 no II Conferência Científica da UFRGS 'A Pesquisa e Novos Paradigmas da Sociedade'.

** Professor do IFCH/Unicamp.
} 
este nível de recursos? A resposta era cruel - eles seriam vistos como preguiçosos, como palhaços ou como ideólogos defensores da anticiência e do obscurantismo! O advento de revolução informacional nas Ciênciais Sociais, por colocar professores, pesquisadores e alunos em contato com um amplo universo de informações, ameaça os defensores do obscurantismo e, talvez por isso, do mesmo modo que a generalização da alfabetização no passado, seja tão combatida.

Mas a revolução informacional não apenas apresenta novos recursos aos cientistas sociais, ela também abre novos campos de pesquisa: engenharia genética, o papel dos meios tecnológicos em governança, organizações virtuais, interação em ambientes virtuais e, num sentido mais aplicado, design de sistemas informacionais. Várias áreas de pesquisa vão necessariamente sofrer transformações: a sociologia do desenvolvimento, a sociologia da juventude, antropologia urbana, administração pública entre outras.

\section{Tecnologias de busca e classificação}

Neste texto, pretendo concentrar-me sobre as ramificações do desenvolvimento da inteligência artificial para as ciências sociais em geral, e, de maneira mais específica, para a Sociologia. Muitas das tecnologias que estão sendo desenvolvidas permitem, pelo menos, fazer mais em menos tempo e com maior qualidade. Quando buscamos 'Max Weber' dentro de um fichário manual, nossos dedos passam de ficha em ficha seguindo o processamento de nosso cérebro, e sabemos que estamos chegando naquilo que interessa quando encontramos 'Marvin Weber' e que fomos além, quando encontramos a ficha de 'Mirian Weber'. O desenvolvimento de fichários informatizados reduz, de maneira significativa, as possibilidades de erro no ato da catalogação e também o tempo passado nestas operações de pesquisa. 
A idéia da pesquisa informatizada agora se espalha para outras áreas. Podemos estar, por exemplo, trabalhando na análise de centenas de páginas de transcrições de uma pesquisa de campo, e queremos saber qual entrevistado falou sobre 'Max Weber' e o que ele falou; se as transcrições foram digitalizadas, a busca desta resposta através da função 'procurar' de um programa de editoracão de textos é muito mais fácil do que se a busca fosse manual. Ou seja, este uso da operação 'procurar' aumenta nossa capacidade de produzir respostas rápidas a perguntas precisas e pontuais.

Um terceiro tipo de operação é, do ponto de vista do pesquisador, mais importante. Programas especializados, tais como o NUD*IST (agora NVivo), Ethnograph e outros, permitem a catalagoção automatizada de palavras em linguagem natural, imagens, conceitos e codificações desenvolvidos pelo pesquisador. Assim, uma das técnicas mais antigas das ciências sociais, a análise de conteúdo, é potencialmente transformada com o advento desses programas. Essas tecnologias informacionais replicam várias atividades mecânicas e rotineiras do pesquisador e, porque permitem ao pesquisador pedir comparações sistemáticas e econômicas entre diversas categorias de dados, ajudam-no a classificar seus dados, a interconectar classes de dados e, a partir disso, a perceber a freqüência, forma e conteúdo de certas relações entre classes de dados. Não apenas uma parte do suor e da chatice deste tipo de pesquisa é eliminado, mas também a qualidade da pesquisa aumenta porque permite comparações sistemáticas a serem feitas (sem gastos excessivos de tempo e recursos) de modo a testar noções e hipóteses. Assim, a informatização aumenta nossa capacidade de cruzar informações, construir e reformular conceitos à luz do progresso na análise, bem como teorizar de maneira indutiva.

Isso faz com que algumas pesquisas, antes inviáveis por causa do tempo que seria necessário, passam a ser possíveis. Hoje em dia, devido à informatização crescente da sociedade, temos um número enorme de dados que existem em forma digital. Jornais e revistas são publicados em CDRom, permitindo que qualquer aluno de graduação compare de maneira 
Sociologias, Porto Alegre, ano 3, no 5, jan/jun 2001, p.58-79

sistemática o tratamento dado por diferentes jornais ao mesmo fenômeno: crime, gênero, políticas sociais, movimentos sociais, campanhas políticas (Fan, 1997). Organizações complexas de todos os tipos também produzem uma grande variedade de informação de natureza quantativa e qualitativa em forma digitalizada para uso interno. Um sociólogo do trabalho poderia facilmente sentir-se afogado pelo excesso de informações disponíveis, mas, se ele for treinado no uso de programas de planilha (ex. Excell), de um lado, e de análise quantitativa de dados qualitativos (ex. NUD*IST), do outro, terá a seu dispor ferramentas que lhe permitirão classificar e analisar esse material da maneira mais completa possível, o que teria sido impossível usando técnicas de pesquisa tradicionais. Este tipo de tecnologia informacional acaba funcionando de maneira análoga ao microscópio, permitindo enxergar aquilo que era nebuloso, de maneira mais nítida e enxergar aquilo que antes era invisível a olho nu. Mas, sem uma formação teórica, uma imagem aumentada pelo microscópio apenas aparece mais bonita! Não basta só ver melhor e em maiores detalhes, é preciso saber interpretar aquilo que está sendo observado graças ao uso dessas tecnologias. Até o presente momento, nenhuma tecnologia conseguiu substituir o trabalho teórico que o pesquisador tem de fazer para que seus dados passem a ter significado no campo da ciência.

Um primeiro problema que surge com isto é como essas tecnologias informacionais podem ser usadas por pessoas com uma inadequada formação teórica, ou seja, mesmo que as pesquisas tenham sido bem realizadas de ponto de visto técnico, as análises produzidas acabarão não tendo substância, do ponto de visto teórico. Um segundo problema é que a disponibilidade e a predominância dessas tecnologias acaba dominando a escolha de problemas. No limite, apenas problemas capazes de serem pesquisados empregando essas tecnologias seriam considerados legítimos, assim definindo outros problemas de grande relevância como ilegitimos.

Nesta introdução, falei em duas coisas que estão acontecendo: em primeiro lugar pesquisadores estão empregando recursos informacionais para 
alavancar suas capacidades de analisar grandes quantidades de dados. Assim, uma pesquisa que, no passado, consumia grandes recursos humanos de assistentes de pesquisa trabalhando em tarefas bastante repetitivas, pode agora ser feita por um pesquisador que sabe manipular certos programas de computação, que tem uma boa intuição sociológica e compreensão da construção de teoria. Em segundo lugar, a crescente informatização de registros e outros dados sobre múltiplos aspectos da vida social transforma a estrutura básica do sistema de aprendizagem em ciências sociais. Dessa forma, o professor especialista em transmitir séries de dados a respeito do mundo perde seu lugar para o professor que ajuda o aluno a interpretar os dados que ele mesmo colheu. Assim o professor ensina cada um a virar seu próprio teórico.

\section{A Inteligência Social Artificial}

A Inteligência Artificial é definida como:

a capacidade de um computador digital ou aparelho robótico controlado por um computador a cumprir tarefas normalmente associadas com processos intelectuais superiores, caraterísticas de seres humanos tais como capacidade de raciocinar, descobrir significados, generalizar ou aprender a partir de experiências do passado. Se usa a expressão para se referir aquele ramo da ciência da computação que cuida do desenvolvimento de sistemas dotados com tais capacidades (Encyclopaedia Britannica).

Dentro deste contexto, Bainbridge et ali. definem a inteligência so- 
cial artificial como a aplicação de técnicas de inteligência mecânica a fenômenos sociais.... inclusive construção de teoria e análise de dados (1994, p. 408). Os autores se referem à representação da vida em sociedade, grupos ou organizações, através de processos de modelagem que produzem simulações do comportamento humano em determinados contextos. Eles também discutem o uso de técnicas de inteligência artificial para ajudar com a pesquisa e a análise de dados.

Desde a década de 40, cientistas sociais têm refletido sobre como teorias de computação e cibernética podem transformar suas ciências e formar uma base da interdisciplinaridade. A idéia da aplicação de técnicas de inteligência artificial (IA) à análise do mundo social começou a se cristalizar em meados da década de 80, quando um congresso na Inglaterra resultou na publicação do livro Ação Social e Inteligência Artificia/de Gilbert e Heath (1985). A noção tem respaldo na Antropologia (Chablo, 1996) e na Ciência Política (Kimber, 1991) e também em áreas próximas à nossa: Psicologia, Saúde Pública, Criminologia, Administração e Economia.

\section{O que a Sociologia pode fazer para a Inteligência Artificial?}

No livro Mind over Machine os irmãos Dreyfus escreveram, nos últimos anos, que a pesquisa sobre a IA nos ensinou muito sobre nós mesmos, mais por seus fracassos do que pelos sucessos (Dreyfus e Dreyfus, 1986, p. 11). Collins diz em 1992 que ele imaginava ser impossível desenvolver uma IA de grande alcance, sem recorrer à Sociologia. Como a Sociologia pode contribuir para o projeto de construção de IA? O modelo tradicional de IA é construído na base da idéia de que uma pessoa age como indivíduo dentro do mundo, e não de uma pessoa dentro de um sistema de interações sociais, que existe dentro do mundo. Esta simplificação produz como referência central uma relação entre IA e a psicologia cognitiva, o projeto da IA de simular o comportamento de um (ou mais) ator humano. A noção de 
Sociologias, Porto Alegre, ano 3, no 5, jan/jun 2001, p.58-79

inteligência usada ignora o fato central à sociologia interacionista de que interagimos com outros seres humanos em contextos sociais. Mas estes esforços de construção da IA não simulam o comportamento do ator humano numa relação social.

Doran propõe em Gilbert e Heath (1985) que uma área interessante é a ação social, onde a IA busca construir sistemas nos quais múltiplos 'atores virtuais' cooperam na execução de uma tarefa em comum. É preciso um enorme trabalho para representar, em forma computacional, esses atores. Para Doran, a agenda de pesquisa inclui: como representar os Conhecimentos e crenças de um ator; como agregar atores numa entidade maior; como garantir que os atores memorizem seus projetos, de modo a poder acessá-los de maneira adequada? Hoje existem outros projetos que trazem uma contribuição sociológica ao desenvolvimento da IA (Prietula, Carley e Gasser, 1998). Ou seja, há uma contribuição da sociologia para o desenvolvimento de técnicas de IA em algumas áreas da ação humana.

Que contribuição a IA e outras tecnologias informacionais podem trazer para o desenvolvimento da Sociologia?

* Entrevistando com a ajuda de tecnologias de Inteligência Artificial

Desde a década de 60, pesquisadores estão desenvolvendo programas que entrevistam. No seu último livro, Sherry Turkle conta um pouco da história da penetração desta tecnologia dentro da psicoterapia, e os argumentos dos desenvolvedores a respeito do programa ELIZA (que ocorreram entre o final dos anos 70 e meados dos anos 80). Em meados da década de 80 , surgiram programas concebidos para auto-ajuda, e estes auxiliaram usuários a relaxar, evitar crises depressivas, fazer um regime ou desenvolver um programa de exercícios físicos. Baseada em técnicas de múltipla-escoIha, essa tecnologia passou a ser representada de maneira favorável na 
imprensa. Em 1990, um estudo comparou 3 grupos de pessoas com sintomas de depressão: aquele tratado com psicoterapia, aquele tratado com psicoterapia informatizada e um grupo de controle. Após 6 semanas de tratamento, os dois primeiros grupos alcançaram os mesmos índices de melhoras de saúde. O programa Depression 2.0 é construído em torno de uma teoria cognitivo-comportamentalista facilmente modelada num computador. Após uma entrevista, o usuário estabelece os fatores que estão gerando sua depressão, aceitando ou rejeitando as 'posições' tomadas pelo programa conforme a utilidade emprestada a cada pergunta e a resposta dada pelo programa. Ou seja, alguns pacientes com necessidade de tratamento psicoterapêutico passaram a aceitar ser entrevistados por uma máquina dotada de um grau de inteligência artificial e ter caminhos de ação 'recomendados' pela máquina (Turkle, 1996, p. 102-124).

Nas Ciências Sociais, investiga-se o uso dessa mesma tecnologia para administrar entrevistas. Três vantagens são observadas: primeira, a maior facilidade em receber respostas a perguntas sobre temas delicados; segunda, a possibilidade de usar hipertextos para direcionar a entrevista e assim aprofundar questões específicas e, na hora de tabular as respostas, realizar grandes economias de tempo e esforço; terceira, a realização de sondagens de opinão pública pela internet. Com respeito à primeira vantagem, a entrevista automatizada oferece uma maior facilidade em receber respostas a perguntas sobre temas delicados (pessoas entrevistadas sobre sexualidade ou corrupção, por exemplo, podem responder mais facilmente a uma máquina do que a um ser humano) (Johnston e Walton, 1995). Nos Estados Unidos, durante o recente 'National Household Survey on Drug Abuse', realizou-se uma experiência com entrevistas assistidas por computador e se descobriu um aumento nos relatos de uso de drogas em relação à entrevista tradicional e, também, o programa permitiu aos entrevistados corrigir inconsistências (detectadas por computador) nas respostas (Lessler et ali, 2000). Com respeito à segunda vantagem, além de poder melhor direcionar as entrevistas e poder interrogar entrevistados sobre insconsistências nas 
respostas, na hora de tabular as respostas há grandes economias de tempo e esforço. Em relação à terceira vantagem, sondagens de opinão pública podem, num futuro próximo, ser realizadas através da internet. Famílias de baixa renda serão incluídas na amostra, através da doação de computadores e ligações à internet. Experimentos já estão demostrando a validade das respostas obtidas com esta abordagem (Featherman, 2000), e, para Bainbridge (1999), uma grande vantagem da adoção dessa técnica é a redução de custos da pesquisa.

* Extensão da capacidade de leitura e classificação de textos

Nos últimos anos, desenvolveu-se uma série de programas que são capazes de ler textos e classificar suas partes - sejam estes escritos ou visuais. Num primeiro momento, o pesquisador constroí suas categorias de análise e, num segundo momento, grandes quantidades de informações podem ser classificadas automaticamente conforme os padrões fixados pelo pesquisador para, em seguida, serem analisadas. Programas do tipo Nud*ist e seu substituto NVivo, Ethnograph, Atlas/ti e HyperResearch são exemplos. Outros artigos nessa revista analisam o uso desses programas e, por esta razão, não convém entrar em detalhes aqui. Basta dizer, em primeiro lugar, que um grande leque de documentos pode ser analisado com a ajuda desses programas: partes não-gráficas de páginas na web, jornais preservados em CD-Rom, anais de congressos, relatórios de organizações, dialógos em salas de bate-papo na internet e até imagens digitalizadas. Esses programas agora facilitam a execução de pesquisas antes consideradas impossíveis ou excessivamente caras.

Hoje é possível fazer análises assistidas por computadores, que sejam comparativas tanto no tempo quanto no espaço, análises que examinam muitas dimensões não apenas da vida política e social mas também intelectual. Por exemplo, o fato de que bibliografias de artigos e livros pos- 
sam ser digitalizadas permite o mapeamento, através da análise de citações, dos 'colégios invisíveis' que sustentam as carreiras e o desenvolvimento intelectual dos autores (Baldi, 1998).

No passado, quando um pesquisador queria sistematizar conhecimentos numa área, fazendo um 'estudo dos estudos', era necessário codificar os documentos manualmente. Hoje a emergência de tecnologias informacionais permite a análise de documentos digitalizados, assistida por computador. Desde, pelo menos, a década de 40, existem excelentes 'estudos de estudos' que revelam com freqüência descobertas suprendentes. No livro 'Social Structure' Murdoch (1949) analisou 250 sociedades na base de estudos feitos por mais de 250 pesquisadores. Entre suas múltiplas descobertas há várias surpresas, por exemplo, o relacionamento familiar, de longe o mais observado (em 137 sociedades), foi aquele entre o marido e sua sogra; o segundo mais observado foi entre o marido e a irmã de sua mulher (88 sociedades). Para classificar a natureza do relacionamento entre o marido e sua sogra, Murdoch desenvolveu uma escala de 5 pontos indo de 'frio' a 'caloroso'.

Nenhuma sociedade observada permite a manutenção de relacionamentos classificados como 'calorosos' entre o marido e sua sogra. Na grande maioria dos casos, apenas relacionamentos 'frios' são mantidos. Caplow teoriza, no seu livro sobre teoria triádica, que todo relacionamento entre três pessoas ou entidades resulta na formação de uma coalizão de dois contra um. Na base das informações sistematizadas por Murdoch, Caplow teoriza que o homem mantém um relacionamento distante com sua sogra para evitar que se forme uma relação triádica insustentável na qual a esposa será obrigada a formar uma coalizão ou com seu marido contra sua prórpria mãe ou com sua mãe contra seu marido (Caplow, 1968, 105). As ciências sociais comparadas, desde sempre, baseiam-se em estudos comparativos, ou no tempo ou no espaço. O tipo de trabalho desenvolvido por Murdoch é fruto de um amplo e sistemático 'estudo dos estudos', serve como protótipo, devido à maneira na qual a base de dados usada permite hipóteses de 
cunho comparativo a serem testadas de maneira rigorosa. Hoje em dia, o desenvolvimento de técnicas de análise informatizada nos leva a esperar que o número de análises comparadas, de 'estudos de estudos', aumentará num futuro próximo.

Esse tipo de tecnologia informacional copia a atividade humana, reproduz artificial e rapidamente atos rotineiros de pesquisadores, tais como classificação ou codificação de dados qualitativos, atos que teriam que ser executados manualmente se estas tecnologias não existissem. Uma vez classificados os dados, o pesquisador tem a responsabilidade de aceitar, modificar ou rejeitar as classificações antes de proceder à análise dos resultados.

Essas tecnologias ainda estão em fase de desenvolvimento, a generalização de seu uso depende não apenas da capacitação de professores e técnicos, mas também da resolução de vários de seus conhecidos problemas e do alcançe de um certo nível de aceitação no meio acadêmico. Como Wilma Mangabeira (1996) ensina, o grau de aceitação varia de país a país. É possível que, no futuro, essas tecnologias sejam tão importantes para o desenvolvimento de alguns tipos de análise de natureza qualitativa quanto foi o desenvolvimento de programas computacionais, tais como SPSS e SAS, para o tratamento de certos dados quantitativos.

* Inteligência Artificial e pesquisas que se servem de estatísticas

$\mathrm{Na}$ área de uso de estatísticas, podemos também enxergar a contribuição da IA. Para o pesquisador iniciante, o programa 'Statistical Navigator' o ajuda a decidir quais entre mais de 200 tipos de análise estatística são melhores para seu projeto. Para que o pesquisador consiga escolher bem, há uma entrevista computadorizada a respeito de seus objetivos e prioridades. Após essa entrevista, uma série de alternativas é apresentada ao pesquisador que, através de hipertexto, consegue ter a descrição de cada mé- 
Sociologias, Porto Alegre, ano 3, no 5, jan/jun 2001, p.58-79

todo para ajudá-lo a tomar sua decisão.

* A extensão do olhar humano

Em Vigiar e Punir, Michel Foucault escreve a respeito da importância da extensão do raio de visão humana para a formação de mecanismos de controle social. Ele demonstra a pertinência desta idéia com referência ao Panoptican desenvolvido por Bentham no qual, a partir da arquitetura, uns poucos observadores conseguem supervisionar as atividades de um grande número de pessoas sem, no entanto, serem visíveis.

Hoje as instituições totais não são mais os únicos lugares onde as atividades humanas podem ser monitoradas por observadores invisíveis. Nos grades centros urbanos, câmeras de vídeo estão sendo usadas de maneira generalizada: na porta de casa, nas ruas, nos shopping centers. Será que estamos cada vez mais presos dentro de um aparelho estilo Panoptican? Vivemos Bentham na época dos Bits? As sociedades vão precisar desenvolver novos mecanismos de proteção da privacidade individual e mecanismos de combate à concentração de poder nas mãos daqueles que observam a sociedade, ou seja, de evitar um estado policial à la '1984 de Orwell'. Na Wired, a revista cultural da sociedade de informação, Brin especula que, se todos os cidadãos tiverem acesso em tempo real às imagens geradas por essas câmeras - haverá uma democratização do controle do sistema de controle social (Brin, 1996 ). Ou seja, em vez de dupla reflexividade, haveria um duplo Panoptican, com os cidadãos observando o trabalho dos agentes policiais, e, ao mesmo tempo, os cidadãos teriam acesso às mesmas imagens da rua, da porta de casa ou do shopping observadas pelos policiais.

Para os cientistas sociais, a geração e armazenamento dessas imagens em forma digital produz um material de pesquisa, como nos mostra o telejornalismo brasileiro, que pode servir a várias finalidades. A pergunta 
que se coloca é qual é a importância da existência dessas imagens para pesquisadores em Ciências Sociais? As respostas já estão começando a ser dadas na prática; para mim, a coisa mais importante é sair da utilização narrativa deste material para alcançar algum nível de análise mais teórico. As tecnologias de tratamento informatizado de imagens permitem o desenvolvimento de classificações de imagens (Evans, 2000). No futuro próximo, o desenvolvimento tanto das tecnologias quanto das capacidades humanas, deve levar a análises sistemáticas e quantitivas de grandes volumes de informações visuais.

Raudensbush e Sampson (1997) descrevem seus esforços de observação sistemática de bairros americanos, usando câmeras de vídeo. Além disso, o estudo envolve um promissor recurso a múltiplos métodos: filmagem de vídeo, entrevistas, dados de censo, dados extraídos de sondagens, estatísticas de patologias sociais e entrevistas. Todos são analisados de modo a apresentar uma visão completa da vida em comunidade. Inspirados pelo conceito de 'observação social sistemática' desenvolvido por Reiss (1971), os pesquisadores buscam construir sua 'ciência' - 'ecometrics'. Numa das inovações metodológicas, os pesquisadores filmaram as ruas principais dos bairros em determinadas horas. Para construir suas análises, os pesquisadores usavam as imagens para complementar e contestar dados recolhidos de outras fontes. Assim, foi possível ter maior clareza sobre descompassos entre os dados sobre processos sociais e as representações desses processos. Devido à capacidade de esta autodenominada 'ciência' integrar dados recolhidos a partir de múltiplas fontes, os autores concluem que a abordagem é bastante promissora para a avaliação confiável e válida de processos sociais em nível de vizinhança (Raudenbush e Sampson, 1997, p. 33). O armazenamento de imagens captadas rotineiramente por câmeras de vídeo representa um primeiro passo para estimular o desenvolvimento de profissionais capazes de analisar imagens através de óticas construídas pelas Ciências Sociais. O segundo passo é estimular grupos de alunos e pesquisadores a ter vontade de analisar a sociedade a partir de suas 'observações da 
Sociologias, Porto Alegre, ano 3, no 5, jan/jun 2001, p.58-79

realidade social' assistidas por computadores e estimular tanto o treinamento técnico quanto a formação teórica dos membros desses grupos.

Mas podemos chegar rapidamente a um dos mais importantes limites da exploração dessas tecnologias informacionais. Limite de onde é possível enxergar a sombra do uso dessas tecnologias que sejam visuais, de áudio ou de texto, por agências de controle social, que agirão de maneira incompatível com os princípios da democracia e respeito à privacidade. No passado, a sociologia desenvolveu técnicas de survey, que acabaram alimentando disciplinas tais como a Ciência Política e o Marketing. Essas disciplinas estimularam a aplicação das tecnologias não mais de maneira científica - mas de modo a aumentar o poder daqueles que as empregavam. $\mathrm{O}$ fato de que as ciências sociais estão explorando essas tecnologias impõe a responsabilidade de desenvolver princípios éticos no uso delas.

\section{Inteligência Artificial e o ensino}

\section{* Programas de computação}

Programas tais como o 'Statistical Navigator' a que me referi acima podem servir de ferramenta de apoio didático num curso de métodos e técnicas. No passado, vimos outros casos em que novas tecnologias contribuíram para parcialmente transformar o ensino; na Antropologia, a introdução de vídeo em sala de aula contribui para transformar o ensino. Hoje a IA ameaça chegar ao ensino.

Na revista Teaching Sociology Brent et ali. (1989) descrevem o programa 'Erving' que simula a perspectiva de Erving Goffman. O usuário vai do palco aos bastidores, assiste à interação de pessoas e vai aprendendo, em termos Goffmanianos, sobre os sistemas de interação social. O computador também pode testar a compreensão que o usuário tem da teoria de Goffman. Ou seja, a tradicional prova de múltipla escolha é refinada, os 
Sociologias, Porto Alegre, ano 3, no 5, jan/jun 2001, p.58-79

resultados saem na hora e sem que nenhum professor precise estressar-se com a atribuição de notas!

Na Universidade Carnegie Mellon, um sistema chamado 'Entrevistas Sintéticas' foi desenvolvido. Para aprender sobre a vida de um teórico ou de sua teoria, você entra numa situação que lembra uma vídeo-conferência. O aluno faz perguntas em linguagem natural e um progama de IA busca nos arquivos de material gravado em vídeo a resposta que o teórico julgaria mais apropriada, transmitindo-a ao aluno. O primeiro teórico incluido é Albert Einstein (Port, 1999, p. 52-53).

\section{* Transformação do ensino}

Algumas tecnologias que empregam IA vão, com certeza, chegar às salas de aula de alunos de ciências sociais. Isto pode acontecer, talvez, do mesmo modo como CD-Roms chegaram às escolas, transformando o ensino de línguas estrangeiras. No Brasil, podemos especular que as Universidades particulares, com seus volumosos recursos financeiros, com posturas que misturam o desejo de ser modernos a finalidades propagandísticas e fortes orientações de reduzir o custo de ensino por aluno, serão as primeiras a adotar estas tecnologias.

No momento atual, o formato tradicional de ensino está sendo abalado em algumas áreas. Na administração de empresas e marketing, Universidades brasileiras estão tendo que se equipar para concorrer com cursos oferecidos através da Internet por Universidades estrangeiras. Em outras áreas, a internet está fazendo uma importante incursão, como demonstrei no começo deste texto, permitindo aos alunos ter fácil acesso a dados atualizados e, assim, contribuindo não apenas para a transformação da relação professor-aluno, mas também do acesso a informações.

É importante lembrar um princípio fundamental da computação. Em todo sistema automatizado, há sempre algo que não pode ser automatizado, 
e, ironicamente, este 'algo' passa a ter um papel cada vez mais crucial, na medida em que a informatização avança. No caso de ensino, este 'algo' é o papel do professor. Numa sociedade de informação, o papel do professor muda, o professor não transmite mais informações, ajuda o aluno a interpretar as informações que ele mesmo recolheu e também estimula o aluno a procurar outras informações, e o aluno, por sua vez, tem que contar com o apoio de bibliotecários profissionais. A compreensão do mundo se desenvolve a partir da capacidade de processar e interpretar informações, dentro de uma construção teórica que tem legitmidade científica (a referência à noção de ciência visa excluir qualquer diálogo com falsas ciências tais como a astrologia e com ideologias que são travestidas de ciências). Dentro deste contexto, faço a hipótese de que haverá uma nítida valorização daqueles professores de Ciências Sociais que saibam construir teoria e que consigam ensinar esta habilidade a seus alunos. (Vê um esforço tipicamente americano de refletir sobre o papel da abordagem computacional na construção de explicações (Brent, Thompson, Vale. 2000)).

\section{Construção de teoria}

As tecnologias informacionais servem para testar hipóteses de pesquisadores e também para gerar novas hipóteses. A partir do momento em que o pesquisador constroí inter-relações lógicas entre hipóteses verificadas, estamos falando na execução de uma das atividades fundamentais das Ciências Sociais: a construção de teoria (Glaser e Strauss, 1967). Há também cientistas que se dedicam a construir 'agentes', ou seja, formas de vida artificial que podem simular comportamentos tanto de animais quanto de seres humanos. Tenta-se desenvolver modelos computacionais que simulam o que acontece em sociedades em caso de guerra, fome, desastres, etc. Os modelos são baseados em observações de comportamentos, em dados empíricos registrados através de observações de muitos casos tanto em termos qualitativos quanto quantitativos. Parece que esses esforços de simulação funcionam melhor quando se 
Sociologias, Porto Alegre, ano 3, no 5, jan/jun 2001, p.58-79

trata de comportamentos que são 'automáticos' e, por esta razão, têm um maior grau de previsibilidade do que ações que embutem um grau de cálculo e reflexividade. A partir de modelos simples de comportamento, Epstein e Axtell (1996) buscam descodificar estruturas e ações coletivas tais como ecossistemas, epidemias, corridas armamentistas, guerrras e descobrir as regras localizadas que geram esses fenômenos. Outros se arriscam a fazer o trabalho teórico necessário para desenvolver simulações de situações sociais mais complexas (Goldspink, 2000). A revista on-line Journal of Artificial Societies and Social Simulation publica artigos científicos sobre o desenvolvimento e uso de modelos de sistemas sociais povoados por múltiplos agentes (www.soc.surrey.ac.uk/JASSS).

\section{Conclusão}

Neste texto, procurei trazer algumas noções das fronteiras do desenvolvimento de tecnologias informacionais que são relevantes às Ciências Sociais. Examinei alguns softwares e projetos, frutos da sociedade de informação, que alavancarão transformações na maneira como se faz Ciências Sociais: no ensino, na pesquisa e na teorização. Uma coisa é certa: as qualificações dos cientistas sociais vão ter de mudar para poder incorporar essas tecnologias, será necessário inclusive que as Ciências Sociais desenvolvam uma relação mais estreita com as ciências da computação, pois seus pesquisadores precisam de nós para desenvolver produtos tais como IA, e muitas vezes, vamos precisar trabalhar juntos para podermos usar as tecnologias informacionais para analisar o mundo social.

Nem tudo o que foi mencionado neste artigo vai incorporar-se à prática dos cientistas sociais. É um fato da sociedade de informação que as pessoas, muitas vezes, atribuem às tecnologias capacidades muito maiores que elas conseguem demonstrar na prática. Neste caso, o cientista social pode ser levado a um beco sem saída por modismo. 
Vou agora abandonar um pouco o foco anterior sobre IA para falar em termos mais amplos. Existe uma rede mundial de computadores, existem muitos CD-Roms espalhados pelas bibliotecas de Ciências Sociais no Brasil, o Projeto Prossiga de bibliotecas virtuais é apoiado pelo CNPq, bancos de dados são regularmente compilados sobre os mais diversos temas, sites de internet estão brotando com dados governamentais (Lavoratti, 2000), relatórios até com dados comparativos. O desafio é juntar estas diversas fontes de informação, de modo a melhorar o acesso que os cientistas sociais brasileiros têm aos dados e às informações. Há quase meio século, a UNESCO defende o desenvolvimento de grandes e sistemáticas comparações internacionais. Ryssevik (1994) lança a idéia de Laboratórios Sociais Virtuais integrando dados, de modo a facilitar certas pesquisas comparadas. Outros desenvolvem projetos de observatórios sociais. Um desses projetos tem um nome evocativo - o 'Social Hubble' (SMBH, 2000). Estes projetos e idéias visam fortalecer nossa capacidade de desenvolver análises comparativas. No futuro, parece inevitável que as tecnologias informacionais, inclusive a inteligência social artificial, vão contribuir de maneira crescente para o desenvolvimento de nossa ciência.

\section{Referências bibliográficas}

BAINBRIDGE, W. S. et ali. Artificial Social Intelligence. Annual Review of Sociology. vol 20, 1983. 407-436.

BAINBRIDGE, W. S. Cyberspace: Sociology's Natural Domain. ContemporarySociology; 28, 6, p. 664-667, nov 1999.

BALDI, S. Normative versus Social Constructivist Processes in the Allocation of Citations: A network-analytic model. American Sociological Review. vol. 63, p. 829-846. 1998. 
BANERJEE, S. Reproduction of Social Structures: An artifical intelligence model. Journal of Conflict Resolution. vol. 30, p. 221-252. 1986.

BODEN, M. A. Artificial Intelligence and Social Forecasting. Journal of Mathematical_Sociology. vol. 9, 4, p. 341-356. 1984.

BRENT E. E. et ali.. Erving: A program to teach sociological reasoning from the dramaturgical perspective. Teaching Sociology. vol. 17, p. 38-48. 1989.

BRENT, E. , THOMPSON, A. e VALE, W. Sociology: A computacional approach to sociological explanations. Social Science Computer Review. vol. 18, p. 223-235. 2000.

BRIN, D. The Transparent Society. Wired. vol 4, n. 12, p. 260-262 e p. 304-309. 1996.

CAPLOW, T. Two Against One: Coalitions in Triads. Englewood Cliffs, PrenticeHall. 1968.

CHABLO, A. What Can Artificial Intelligence Do for Anthropology? Current Anthropology. Vol. 37, p. 553-555. 1996.

COLLINS, R. Sociological Insight : An introduction to non-obvious sociology. 2. ed. New York, Oxford University Press. p. 155-184. (Can Sociology Create an Artificial Intelligence?). 1992.

DREYFUS, H. L. e DREYFUS, S. E. Mind over machine: The power of human intuition_Expertise in the era of the computer. New York, Free Press. 1986.

Encyclopedia Britannica. 2001. Artificial Intelligence. Herbert A.Simon (www.britannica.com)

EPSTEIN, J. M. e AXTELL, R. Growing Artificial Societies: Social sceince from the bottom up. Washington, DC, Brookings Institute. 1996. Disponível na internet: 
Sociologias, Porto Alegre, ano 3, no 5, jan/jun 2001, p.58-79

http://www.brook.edu/sugarscape/links.htm.

EVANS, W. Teaching Computers to Watch Television: Content-based image retreival for content analysis. Social Science Computer Review. vol. 18, p. 246-257. 2000.

FAN, D. F. Computer Content Analysis of press Coverage and Prediciton of Public Opinion for the 1995 Sovereignty Referendum in Quebec. Social Science Computer_Review. vol. 15, p. 351-366. 1997.

FEATHERMAN, D. conversa particular com David Featherman, Diretor do Institute for Survey Research da University of Michigan em Belo Horizonte, 19 junho . 2000.

GLASER, B. e STRAUSS, A. The Discovery of Grounded Theory. Chicago, Aldine Publishing. 1967.

GILBERT, G. N. Heath, C. Social Action and Artificial Intelligence: Surrey conferences on sociological theory and method 3. Aldershot, Gower Publishing. 1985.

GOLDSPINK, C. Modelling Social Systems as Complex: Towards a social simulation meta-model. Journal of Artificial Societies and Social Simulation. vol. 3, no. 2. 2000. Disponível na internet: www.soc.surrey.ac.uk/JASSS/3/2/1.html.

JOHNSTON, J. e, WALTON, C. Reducing response effects for sensitive questions: A computer-assisted self interview with audio. Social Science Computer Review. vol 13, p. 304-319. 1995.

KIMBER, R. Artificial Intelligence and the Study of Democracy. Social Science Computer Review. vol. 9, p.381-398. 1991.

LAVORATTI, L. Choque de transparência vai incluir Internet. Estado de São Paulo, 17 de agosto, A 4. 2000. 
Sociologias, Porto Alegre, ano 3, no 5, jan/jun 2001, p.58-79

LESSLER, J. T. et ali. Developing Computer Assisted Interviewing (CAI) for the National Household Survey on Drug Abuse. Journal of Drug Issues. vol 30, p. 9-34. 2000.

MANGABEIRA, W. CAQDAS and its Diffusion Across four Countries: National Specificities and Common Themes. Current Sociology. vol. 44, n. 3, p.191-205. 1996.

MURDOCH, G. P. Social Structure. New York, Macmillan. 1949.

PORT, O. The Mind is Immortal. Business Week. August 30, p. 52-53. 1999.

PRIETULA, M.J., CARLEY, K.M. e GASSER, L. (orgs) . Simulating organizations: Computational models of institutions and groups. Menlo Park, AAAI Press e MIT Press. 1998.

RAUDENSBUSH, S. W. e SAMPSON, R. J. Ecometrics: Toward a science of assessing ecological settings, with application to the systematic social observation of neighbourhoods. Paper apresentado as encontro annual da 'American Society of Criminology', San Diego. 1997.

REISS, A. J. Systematic Observations of Natural Social Phenomena. Sociological Methodology. COSTNER, H. (org.) San Francisco, Jossey-Bass. p. 3-33. 1971.

RYSSEVIK, J. Laboratories for Comparative Social Science. International Social Science Journal. n. 142, p. 587-596. 1994.

$\mathrm{SMBH}$. Seminário Survey Metropolitano de Belo Horizonte. Belo Horizonte, FAFICH/UFMG. 19-21 de junho. 2000.

TURKLE, S. Life on the Screen: Identity in the age of the internet. London, Weidenfeld \& Nicholson. 1996. 
Sociologias, Porto Alegre, ano 3, no 5, jan/jun 2001, p.58-79

\section{Resumo}

Este artigo analisa algumas possibilidades de transformação das Ciências Sociais e, de maneira mais específica, na Sociologia, levantadas a partir do desenvolvimento e uso, nessas ciências, de tecnologias informacionais. Nas sociedades contemporâneas o aprofundamento do uso destas novas tecnologias pode trazer importantes conseqüências para as Ciências Sociais afetando, potencialmente, o ensino, a pesquisa e a construção de teoria. No Brasil podemos ver que um número crescente de informações é disponível em formato eletrônico, e estas podem ser analisadas para aumentar nossos conhecimentos sobre a sociedade. De fundamental importância é que o crescente recurso a tecnologias informacionais seja acompanhado por avanços na capacidade de teorização.

Palavras-chave: tecnologias informacionais, inteligência artificial, metodologia. 